\title{
The heterogeneous influence of economic growth on environmental pollution: evidence from municipal data of China
}

\author{
Zhen Huangfu ${ }^{1} \cdot \mathrm{Hui} \mathrm{Hu}^{2,3} \cdot \mathrm{Nan} \mathrm{Xie}^{4} \cdot$ Yu-Qi Zhu ${ }^{3} \cdot \mathrm{HaO} \mathrm{Chen}^{3} \cdot$ Yang Wang $^{3}$
}

Received: 1 December 2019 / Published online: 28 April 2020

(c) The Author(s) 2020

\begin{abstract}
This study aims to investigate the influence of rapid economic development on pollution at the municipal level in China. It constructs a Stochastic Impacts by Regression on Population, Affluence and Technology model (STIRPAT model) and uses comprehensive municipal data on industrial pollution and economic performance. The dataset contains 290 cities from 2003 to 2016 as a sample for the panel data analysis. The study further separates the cities into two groups by their levels of economic development for heterogeneity analysis. It reveals that a low level of economic development would aggravate environmental pollution, and when the economy reaches a high level, this economic development will improve environmental quality. We also find that the relationships between foreign direct investment and industrial dust and sulfur dioxide $\left(\mathrm{SO}_{2}\right)$ discharge are significant, while the relationship between economic growth and effluent emission is not. The more developed subsample cities present an inverted U-shaped curve between industrial pollutant emission, GDP per capita, and foreign direct investment, while the less developed subsamples show no such relationship. Since the shape of these curves differs among regions, their turning points vary accordingly. Based on this finding, this study suggests that the governments of more developed cities should balance environmental pollution and economic development by enhancing environmental regulations and adjusting industrial structure.
\end{abstract}

Keywords Environmental pollution $\cdot$ Economic development $\cdot$ China $\cdot$ Municipal data $\cdot$ STIRPAT model $\cdot$ Heterogeneity

\section{Introduction}

The reform and opening-up policy in China have promoted continuous and rapid economic growth. After China joined the WTO, the average growth rate of China's GDP went up 9.5\% from 2003 to 2016. In 2007, the growth rate of the real GDP even hit 14.8\% (World Bank 2020). However, China's industrial structure concentrates on labor-intensive and

Edited by Xiu-Qiu Peng

Hui $\mathrm{Hu}$

hui.hu@whu.edu.cn

1 School of Economics and Management, Tsinghua University, Beijing 100084, China

2 Economic Development Research Centre, Wuhan University, Wuhan 430070, Hubei, China

3 School of Economics and Management, Wuhan University, Wuhan 430070, Hubei, China

4 Antai College of Economics and Management, Shanghai Jiao Tong University, Shanghai 200240, China natural resource-intensive industries. Meanwhile, this fact has caused problems such as the waste of natural resources and the pollution of the environment. After this high-speed period, the economic growth rate decreased to around $6.1 \%$ in 2019, showing the slowdown of the economy.

One of the most severe environmental problems from 2003 to 2016 was the hazy weather caused by air pollution. It was reported by China's Ministry of Ecology and Environment in 2019 that only 121 cities among 338 major cities had their air pollution levels within the national standard in 2018, accounting for $35.8 \%$. As for the other 217 cities, the average air pollution exceeded the standard levels and turned out to be potentially harmful to human health. In other words, severe air pollution has existed in most Chinese cities for recent years.

Hazy weather appears in some Chinese metropolises, such as Beijing. In 2013, the State Council of China issued the Air Pollution Prevention and Control Action Plan, proposing that the government should take action to reduce air pollution. Since the public is increasingly demanding a better environment, it is exceptionally urgent to reveal the 
relationship between economic growth and environmental protection, as well as figure out the balance between these two issues in the period of economic transformation. Therefore, it is vital to realize the significance of environmental pollution. The industrial emission of dust, sulfur dioxide $\left(\mathrm{SO}_{2}\right)$, and effluent are sorted out from the China Statistical Yearbook and shown in Fig. 1.

The pollutants shown in the figure are currently the major industrial pollutants causing environmental pollution in China. From 2003 to 2015, the emission of effluent increased gradually and declined slightly in 2016 . When considering the emissions of sulfur dioxide $\left(\mathrm{SO}_{2}\right)$ and industrial dust, both of them have two peaks during the period from 2003 to 2016. From 2003 to 2006, and from 2010 to 2011, there were two peaks in sulfur dioxide $\left(\mathrm{SO}_{2}\right)$ emission, while between 2006 and 2011, as well as the period after 2011, the discharge of sulfur dioxide $\left(\mathrm{SO}_{2}\right)$ is seen to decline. The situation of industrial dust emission is similar. Besides the period from 2010 to 2011, there was a sharp rise in the discharge of industrial dust and a small increase in $\mathrm{SO}_{2}$ emission. After the Air Pollution Prevention and Control Action Plan in 2013, the discharge of industrial dust and $\mathrm{SO}_{2}$ decreased quickly.

Meanwhile, due to the negative impact of the global financial crisis on China's economic growth, the slowdown of economic growth resulted in a decrease in pollutant emissions during that period. This could be because many factories and firms were closed and thus reduced pollution. According to the current situation, the environment in China is worrying because of the enormous amount of industrial pollutants. Therefore, to reduce levels of environmental pollution, we have to conduct further research into the economic factors related to environmental pollution.

This study aims to investigate the relationship between environmental pollution and economic development at the municipal and regional levels during the high-speed development period. There was a paper claimed that the relationship between environmental pollution and economic growth could be expressed by a Stochastic Impacts by Regression on Population, Affluence and Technology model (STIRPAT model) (Rosa and Dietz 1997). In our paper, we set GDP, foreign direct investment, industrial structure population, and economic density as dependent variables to analyze their influences on the environment. This model uses the most comprehensive city-level data compiled on industrial pollution and economic performance. The dataset contains 290 Chinese cities from 2003 to 2016 as a sample for the panel data analysis. The paper also separates the sample cities into two groups by their economic development level for heterogeneity analysis.

The organization of the paper is as follows: after introduction, Section two reviews the related studies; section three is the description of variables and model setting; section four presents the empirical analysis based on the fixed-effect model; the final section comes to the conclusions and policy suggestions.

\section{Literature review}

There is an enormous amount of literature on the relationship between environmental pollution and economic growth. Among these, the relationship in environmental pollution and economic development can be described using the inverted U-shaped hypothesis (Kuznets 1955; Grossman and Krueger 1995). Their study concluded that the relationship between the emission of $\mathrm{SO}_{2}$ and economic growth fits the environmental Kuznets curve (EKC). Moreover, there were additional studies proved the existence of the EKC (Shafik and Bandyopadhyay 1992; Panayotou 1993; Selden and

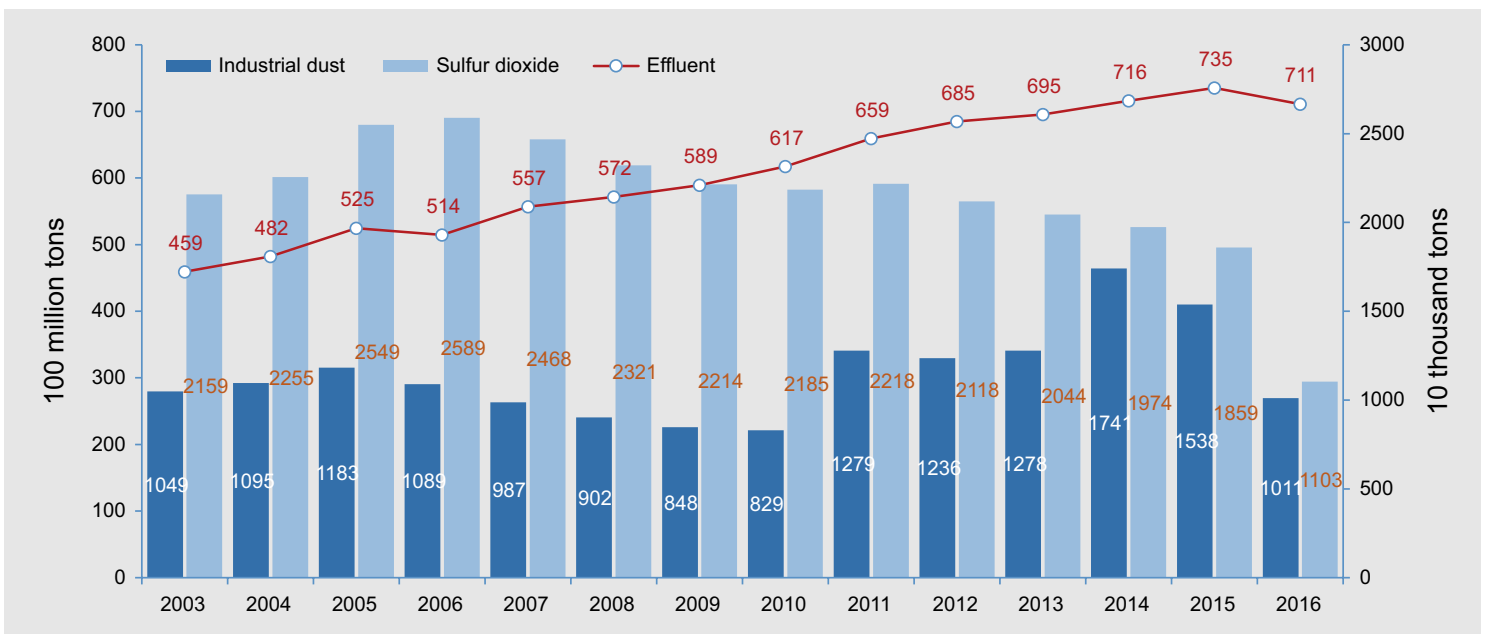

Fig. 1 Volume of main industrial pollutants in China from 2003 to 2016. Data resource: China Statistical Yearbook 
Song 1994). They used cross-countries dataset and proved the existence of EKC hypothesis. There were some other evidences proved that the EKC hypothesis exists in the $\mathrm{CO}_{2}$ emission and economic development using the cross-country data (Coondoo and Dinda 2002). Meanwhile, some literature reviews were made in investigating the environmental Kuznets curve (Dinda 2004).

Recently, many studies also confirmed the existence of the environmental Kuznets curve. A GMM model was tested with 14 Asian countries' $\mathrm{CO}_{2}$ emission data from 1990 to 2011 to confirm the EKC hypothesis (Apergis and Ozturk 2015); supportive evidence of the existence of environmental Kuznets curve (EKC) was funded in 15 Asian countries' 1960-2013 panel data (Apergis 2016). Another paper studied $\mathrm{CO}_{2}$ emission in 25 African countries from 1980 to 2012; it also found supportive evidence for the $\mathrm{EKC}$ in $\mathrm{CO}_{2}$ emission and renewable energy consumption (Zoundi 2017). The OECD countries' data also supported the existence of the EKC (Churchill et al. 2018).

However, the 77 developing countries' dataset from 1971 to 1997 showed that the typical EKC relationship did not exist between economic growth and environmental pollution (Aslanidis and Iranzo 2009). Meanwhile, some researchers suggested that because of the differences among regions, there were still various relationships between pollution and economic growth besides the inverted U-shaped EKC. For example, the $\mathrm{N}$-shaped curve, inverted $\mathrm{N}$-shaped curve, and dumbbell-shaped curve could also somehow fit the relationships (Galeotti et al. 2009). There was one paper using China and India's data from 1971 to 2012 to examine the EKC hypothesis and found an $\mathrm{N}$-shaped relationship between $\mathrm{CO}_{2}$ emissions and economic activity (Pal and Mitra 2017). These studies all use cross-countries' data to verify the hypothesis of EKC, and they have reached different conclusions with different model settings or indicators.

For the economic development and environmental pollution problem in China, one typical research used multiple provinces' pollutant emissions from 1985 to 2004 and examined income per capita with multiple pollutants like effluent and exhaust gas. It found that different pollutants had different shapes of EKC (Song et al. 2006). Besides, there were more studies examined the correlation between economic growth and the volume of $\mathrm{SO}_{2}$ emission (Cai et al. 2008; Llorca and Meunié 2009). Recently, one paper used provincial panel data together with semi-parametric panel fixed-effect regression and found an $\mathrm{EKC}$ for $\mathrm{SO}_{2}$ emission (Wang et al. 2016).

In detail, there was an $\mathrm{N}$-shaped relationship between the pollution index and GDP per capita when examined the relationship between economic growth and pollution in Jiangsu Province using a simultaneous equations model (Ding and Nian 2010). It used the 1985-2006 yearly data with six different pollutants. Economic growth is the direct factor in increasing $\mathrm{CO}_{2}$ emissions. The relationship between $\mathrm{CO}_{2}$ and FDI is shaped like an inverted $\mathrm{U}$ curve, while the relationship between environmental pollution and GDP is more like a ' $M$ ' shape (Liu and Yan 2011). Another published study investigated 27 provinces in China and analyzed their national economic growth and environmental pollution using a panel smooth transition model. They concluded that different forms of relationships could be found by using different pollution indicators (Li et al. 2013).

There was a $\mathrm{CO}_{2}$ Kuznets curve in effect when studied the environmental regulations and $\mathrm{CO}_{2}$ emission (Yin et al. 2015). An inverted $\mathrm{N}$ trajectory between economic growth and $\mathrm{CO}_{2}$ emission was founded when applied a spatial econometric approach (Kang et al. 2016). One recent research analyzed the data of 28 provinces using the system generalized method of moments (GMM) as well as the auto-regressive distributed lag model, and it found strongly supportive evidence for the pollutant emissions matching with EKC ( $\mathrm{Li}$ et al. 2016). Provincial panel data of China spanning the period 2000-2013 were used and the existence of $\mathrm{EKC}$ in $\mathrm{CO}_{2}$ emission was also proved with the provincial data (Wang et al. 2017). Moreover, in large countries with unbalanced economic development, it is necessary to estimate EKC with disaggregate local-level data (Xu 2018). These studies show that with economic development, the situation of the environment deteriorates at the beginning but will improve.

For the research examining the relationship between economic openness and pollution, the 'pollution haven' hypothesis was raised in the last century (Copeland and Taylor 1994). It indicates that some developed countries are more demanding for better environment so they tend to transfer high-polluting industries to developing countries to avoid the high cost of pollutant treatment. As a result, some developing countries become 'pollution havens' for these developed countries. A lot of following studies supported this theory and suggested that two factors cause environmental degradation. First, governments in some developing countries do not strictly supervise the projects operated by foreign investors. Second, these developing countries usually focus on developing resource-intensive industries and exporting resourceintensive products (Javorcik and Wei 2004; Keller and Levinson 2002). However, foreign direct investment (FDI) may improve the environmental quality of the importing countries, as opposed to worsening the environment (Antweiler et al. 2001; He 2010). Some other researches indicated that the influences of FDI on the environment in different regions or different periods are not identical (Su et al. 2011; Zhang and Jiang 2014; Zhu et al. 2019). Hence, the specific influence of the population on pollution still needs further research. It was found that mobile pollution industries had tended to transfer to the areas with loose regulations, while 
the weakly mobile pollution industries had not shown this pollution heaven effect (Dou and Han 2019).

In summary, plenty of studies have examined the relationship between pollution and economic growth in China. Comparing the present studies, we can find that the majority of them have the following characteristics. First, by analyzing the panel data of the cross-countries or provinces, some literature discovers the relationship between economic growth and a certain kind of pollution. Second, some literature only explores the dynamic relationship between economic growth and pollution in a particular city or province. Third, the data of pollutants are analyzed in most other studies via descriptive statistics to uncover the significant pollutants in a region. However, to reveal the relationship between economic development and environmental pollution, it is necessary to study economic growth nationwide. There is a great difference among different sectors (Chen 2010). Some other analyses concentrated only on the relationship between GDP per capita and certain pollutant emission or discharge. For example, some literature studied the heavy metal pollution in China and the waste incineration industry (Hu et al. 2014, 2015). And others studied the carbon dioxide emission with the increase in renewable energy consumption (Dong et al. 2017; Hu et al. 2018; Jiang et al. 2018).

The present study improves the literature in the following aspects: First, considering that a large size of samples is likely to get more precise results, the panel data from 290 cities from 2003 to 2016 are used in this study. Second, given that the explanatory power of GDP per capita is limited in terms of environmental pollution, this study introduces a series of factors related to pollution, such as the opening level of the economy, industrial structure, population, and economy density. Third, existing studies focus on the general pollution index or a particular pollutant, which is far from enough to reflect the situation of pollution nationwide.

This study examines the relationship between economic growth and major pollutants in China, including industrial dust emission, $\mathrm{SO}_{2}$ emission, and industrial effluent discharged. In terms of the research scope, most of the research focuses on a specific region. However, since there are vast differences between different cities whose economic development level varies, the impact of economic growth on the environment is bound to be different. However, the relation between environmental pollution and economic growth in different areas would finally converge to the same level (Brock and Taylor 2010). Since their development patterns could be entirely different, it is necessary to consider the heterogeneity.

This study is the first one to investigate the relationship between economic development and environmental pollution using the municipal panel data of China. It is also the first study to examine the 'pollution haven' hypothesis using city-level panel data of China. It analyzes three different pollutants and investigates economic development and air pollution as well as effluent pollution. Furthermore, it reveals the heterogeneity in different relationships.

\section{Data and method}

\subsection{Variables and data}

The main sources of pollution in China are air pollution and water pollution. To this day, these pollutant emission levels remain high. However, for solid waste pollution, the pollutant emission level has declined by almost $97 \%$. The comprehensive utilization of industrial solid waste has increased to $60.2 \%$ in 2015 (NBS 2016). According to the data from the Ministry of Ecology and Environment, in 2019, industrial $\mathrm{SO}_{2}$ emission was the primary source of air deterioration, and the industrial dust emissions lead to air pollution around the country. The data also show that there is an increasing trend of effluent discharge in the past decades, indicating the equivalent severity of water pollution. The present study selects the industrial emissions of dust, $\mathrm{SO}_{2}$, and effluent discharge as environmental pollution indicators to examine the relationship between national economic growth and pollution. As for solid waste, it is not among the main pollutants in this study as the technologies of the landfill and waste incineration in China are well developed.

According to the STIRPAT model, this paper uses GDP per capita and foreign direct investment (FDI, ten thousand US dollars) to illustrate the level of regional economic growth and economic openness, respectively. The proportion of secondary industry production value in GDP is chosen as the indicator of industrial structure. As a comparison, we also add the services industry share as a control variable to indicate the industrial structure. To explain the regional density of economic activity, the ratio of GDP to the regional area (ten thousand $\mathrm{RMB} /$ square kilometer) is selected as the indicator. This study takes the logarithmic form of some variables to avoid the problem of heteroscedasticity and use the one-period lag to analyze the economic development effect on environmental pollution. The data are from the Statistical Database of Chinese Economic Information Network, the China Stock Market \& Accounting Research Databases, and the China Statistical Yearbook as well as the China City Statistical Yearbook. All variables are shown in Table 1.

For the data part, we use the average value of variables from period $t-1$ and $t+1$ to replace the missing values. From the analysis of summary statistics for all variables (Table 2), it can be seen that the processed panel data are unbalanced. Variables with the sizeable standard error include industrial structure, both the secondary industry and services sector; economy density; and foreign direct investment. The considerably significant 
Table 1 Summary of variables

\begin{tabular}{lll}
\hline Variable & Description & Variable type \\
\hline Lndust & Industrial dust emission $(\log )$ & Dependent variable \\
lnso2 & Industrial $\mathrm{SO}_{2}$ emission $(\log )$ & Dependent variable \\
Lneffluent & Industrial effluent discharged $(\log )$ & Dependent variable \\
Lnpgdp & Per capita GDP $(\log )($ one-period lag) & Independent variable \\
lnpgdp2 & Per capita GDP $(\log )$ square (one-period lag) & Independent variable \\
lnpgdp3 & Per capita GDP $(\log )$ cube $($ one-period lag) & Independent variable \\
lnfdi & Foreign direct investment $(\log )($ one-period lag) & Independent variable \\
lnfdi2 & Foreign direct investment $(\log )$ square $($ one-period lag) & Independent variable \\
Industry & Proportion of secondary industry in GDP (one-period lag) & Independent variable \\
Services & Proportion of third industry in GDP (one-period lag) & Independent variable \\
lnpop & Regional population (log) (one-period lag) & Independent variable \\
lneconomy & Regional density of economic activity (log) (one-period lag) & Independent variable \\
\hline
\end{tabular}

Table 2 Summary statistics of variables

\begin{tabular}{|c|c|c|c|c|c|}
\hline Variable & Observations & Meaning & Standard error & Minimum & Maximum \\
\hline lndust & 3859 & 9.79 & 1.19 & 0.00 & 15.46 \\
\hline lneffluent & 3859 & 17.60 & 1.33 & 0.00 & 20.63 \\
\hline $\operatorname{lnsO}_{2}$ & 3859 & 10.53 & 1.17 & 0.00 & 13.43 \\
\hline $\operatorname{lnpgdp}$ & 3859 & 10.06 & 0.88 & 6.05 & 13.13 \\
\hline $\operatorname{lnpgdp} 2$ & 3859 & 101.93 & 17.89 & 36.63 & 172.53 \\
\hline lnpgdp3 & 3859 & 1040.89 & 275.55 & 221.69 & 2266.10 \\
\hline $\operatorname{lnfdi}$ & 3859 & 9.46 & 2.16 & 0.00 & 14.94 \\
\hline $\operatorname{lnfdi} 2$ & 3859 & 94.06 & 37.16 & 0.00 & 223.24 \\
\hline Industry & 3859 & 48.59 & 10.56 & 15.00 & 88.00 \\
\hline Services & 3859 & 36.88 & 8.59 & 11.10 & 80.20 \\
\hline lnpop & 3859 & 15.10 & 0.66 & 12.01 & 18.25 \\
\hline lneconomy & 3859 & 6.61 & 1.36 & 1.70 & 11.49 \\
\hline
\end{tabular}

differences suggest different levels of economic growth among eastern, central, and western parts of China. With the relatively developed economy and a higher economic openness, the eastern coastal area obtains a higher proportion of foreign investment than the central and western regions.

Furthermore, the large standard error of industrial structure indicates that the differences in the industrial structure and economic development are significant. Furthermore, we also summarize the full sample and do the sample distribution analysis. Table 3 shows that most of our observations come from coastal and more developed provinces like Beijing, Shanghai, Guangdong, Jiangsu, and Fujian. Some of the provinces in inland China, like Tibet, Xinjiang, and Qinghai, lack comprehensive observations. We also can tell that this dataset is an unbalanced panel.

\subsection{Model setting}

When analyzing the relationship between environmental pollution and economic growth, previous study suggested the Stochastic Impacts by Regression on Population, Affluence, and Technology model (STIRPAT model) is of common use (Dietz and Rosa 1997). The model usually sets population, affluence, technology, and related variables as independent variables to analyze their influences on the environment. The model is set as follows:

$I_{i}=\alpha P_{i}^{\beta} A_{i}^{\gamma} T_{i}^{\delta} \varepsilon_{i}$

where $I$ expresses the environment, $P$ is the population; $A$ is the affluence, and $T$ is the technological level. The linear regression equation is given by taking the logarithm of Eq. (1). Moreover, a linear model should combine quadratic 
Table 3 Sample distribution across China. Data source: The Statistical Database of Chinese Economic Information Network, the China Stock Market and Accounting Research Databases, the China Statistical Yearbook, and the China City Statistical Yearbook

\begin{tabular}{|c|c|c|c|c|c|c|c|}
\hline Province & Sample & Total & Percentage & Province & Sample & Total & Percentage \\
\hline Shanghai & 13 & 13 & 100.00 & Jiangxi & 143 & 143 & 100.00 \\
\hline Yunnan & 102 & 208 & 49.04 & Hebei & 141 & 143 & 98.60 \\
\hline Inner Mongolia & 116 & 156 & 74.36 & Henan & 221 & 221 & 100.00 \\
\hline Beijing & 13 & 13 & 100.00 & Zhejiang & 143 & 143 & 100.00 \\
\hline Jilin & 104 & 117 & 88.89 & Hainan & 23 & 65 & 35.38 \\
\hline Sichuan & 233 & 273 & 85.35 & Hubei & 155 & 169 & 91.72 \\
\hline Tianjin & 13 & 13 & 100.00 & Hunan & 169 & 182 & 92.86 \\
\hline Ningxia & 36 & 65 & 55.38 & Gansu & 89 & 182 & 48.90 \\
\hline Anhui & 215 & 208 & 103.37 & Fujian & 117 & 117 & 100.00 \\
\hline Shandong & 220 & 221 & 99.55 & Tibet & 3 & 91 & 3.30 \\
\hline Shanxi & 142 & 143 & 99.30 & Guizhou & 62 & 117 & 52.99 \\
\hline Guangdong & 273 & 273 & 100.00 & Liaoning & 179 & 182 & 98.35 \\
\hline Guangxi & 177 & 182 & 97.25 & Chongqing & 13 & 13 & 100.00 \\
\hline Xinjiang & 15 & 195 & 7.69 & Shaanxi & 125 & 130 & 96.15 \\
\hline Jiangsu & 169 & 169 & 100.00 & Qinghai & 12 & 104 & 11.54 \\
\hline Heilongjiang & 153 & 182 & 84.07 & Total & 3589 & 4420 & 81.20 \\
\hline
\end{tabular}

The total observation is calculated by cities multiplied with years. Anhui had 17 municipal-level cities, but the city Chaohu was degraded to a lower-level city in 2011, so we have a proportion of over 100 through all the periods

and cubic terms and other related factors (Bandyopadhyay and Shafik 1992). Inspired by that, the present study adds GDP per capita, population, foreign direct investment, industrial structure, economy density to the linear model based on current studies. Considering that time effects could exist in panel data, which suggests the existence of two-way fixed effects (two-way FE), a dummy variable $\mathrm{T}$ of year is also added to the regressions. Therefore, the models are presented as follows:

$$
\begin{aligned}
\text { pollution }_{i t}= & c+\alpha_{1} \ln \operatorname{pgdp}_{i t}+\alpha_{2} \ln ^{2} \operatorname{pgdp}_{i t}+\alpha_{3} \ln \text { fdi }_{i t} \\
& +\alpha_{4} \ln ^{2} \text { fdi }_{i t}+\alpha_{5} \ln \text { industry } \\
i t & +\alpha_{6} \ln _{\text {pop }_{i t}} \\
& +\alpha_{7} \ln _{\text {economy }}+\alpha_{8} T+\mu_{i}+\varepsilon_{i t}
\end{aligned}
$$

$$
\begin{aligned}
\text { pollution }_{i t}= & c+\beta_{1} \ln \operatorname{pgdp}_{i t}+\beta_{2} \ln ^{2} \operatorname{pgdp}_{i t} \\
& +\beta_{3} \ln ^{3} \operatorname{pgdp}_{i t}+\beta_{4} \ln \operatorname{fdi}_{i t}+\beta_{5} \ln ^{2} \mathrm{fdi}_{i t} \\
& +\beta_{6} \ln _{i n d u s t r y}+\beta_{7} \ln _{i t} \operatorname{pop}_{i t} \\
& +\beta_{8} \ln \text { economy }_{i t}+\beta_{9} T+\mu_{i}+\varepsilon_{i t}
\end{aligned}
$$

where pollution denotes the pollutant emission or discharge of region $\mathrm{i}$ in year $\mathrm{t}$ and $\mathrm{T}$ is the vector of dummy variables of year. Since the period spans over one decade, there are twelve dummy variables of time. In order to test whether the inverted U-shaped Kuznets curve exists in major Chinese cities, this study adds GDP per capita square (Model 2) and its cubic term (Model 3) to the regression models. In Model 2 , if $\alpha_{2}>0, \alpha_{1}<0$, then the relationship between pollution and economic growth is a U-shaped curve; if $\alpha_{2}<0, \alpha_{1}<0$, then the relationship is an inverse one. Meanwhile, in Model 3 , if $\beta_{3}>0, \beta_{2}<0, \beta_{1}>0$, then the relationship between pollution and economic growth is illustrated as an $\mathrm{N}$-shaped curve; if $\beta_{3}<0, \beta_{2}>0, \beta_{1}<0$, then it is an inverse one. The rest of the explanatory variables are the same as what is shown in Table 1, where i denotes the sample of region $i, t$ denotes the time, $\mu_{\mathrm{i}}$ is the intercept term of individual heterogeneity, and $\varepsilon_{\mathrm{it}}$ is the disturbance term.

\section{Empirical analysis}

\subsection{Empirical analysis of the nationwide sample}

This study uses panel data of 290 cities from 2003 to 2016 for regressions. Data are collected from the continual tracing records of the same group of individuals, which contains not only a cross-sectional dimension (a group of $n$ individuals) but also a time dimension $(T)$. Compared with crosssectional data and time series data, panel data contain not only what is included in cross-sectional data but also what is included in time series data. Hence, the regression analysis can be done in multi-dimensions. Panel data offer more precise results by expanding samples, improving the degree of freedom, and providing more information about the samples.

The main methods of panel data regressions include using a pool regression by taking the sample as cross-sectional data. Another method takes every sample as an independent 
group in a regression function. In practice, panel data regression models are used, including fixed-effect models and random-effect models. Before deciding whether a fixed-effect model or a random-effect model should be used, we need to carry out the Hausman test of robust standard errors for both models. This study uses Stata 15.0 to do the Hausman tests, and results are shown in Table 4.
According to the results, both models reject the null hypothesis at the $1 \%$ significance level. The fixed-effect model should be chosen. This study uses industrial dust emission, industrial $\mathrm{SO}_{2}$ emission, and industrial effluent discharge as explained variables and adopts the fixedeffect regression model of panel data. The full sample regression results are shown in Table 5.

Table 4 Results of Hausman test of clustering robust standard errors

\begin{tabular}{|c|c|c|c|c|c|c|}
\hline \multirow{2}{*}{$\begin{array}{l}\text { Explained variable } \\
\text { Regression model }\end{array}$} & \multicolumn{2}{|l|}{ lndust } & \multicolumn{2}{|l|}{$\operatorname{lnSO}_{2}$} & \multicolumn{2}{|l|}{ Ineffluent } \\
\hline & Model 2 & Model 3 & Model 2 & Model 3 & Model 2 & Model 3 \\
\hline Sargan-Hansen-Stat & 161.44 & 152.98 & 149.87 & 151.66 & 131.86 & 125.06 \\
\hline$P$ value & 0.0000 & 0.0000 & 0.0000 & 0.0000 & 0.0000 & 0.0000 \\
\hline Conclusion & Fixed-effe & & Fixed-eff & & Fixed-eff & \\
\hline
\end{tabular}

Table 5 Empirical results

\begin{tabular}{|c|c|c|c|c|c|c|}
\hline \multirow[t]{3}{*}{ Variable } & (1) & (2) & (3) & (4) & (5) & (6) \\
\hline & \multicolumn{2}{|c|}{ Industrial dust emission } & \multicolumn{2}{|c|}{ Industrial $\mathrm{SO}_{2}$ emission } & \multicolumn{2}{|c|}{ Effluent emission } \\
\hline & Model 2 & Model 3 & Model 2 & Model 3 & Model 2 & Model 3 \\
\hline \multirow[t]{2}{*}{ lnpgdp } & $1.207^{*}$ & -3.835 & $1.739 * * *$ & -1.667 & $1.354 *$ & 3.832 \\
\hline & $(0.613)$ & $(4.280)$ & $(0.534)$ & (3.698) & $(0.772)$ & $(2.837)$ \\
\hline \multirow[t]{2}{*}{$\operatorname{lnpgdp} 2$} & 0.023 & 0.538 & $-0.073 * * *$ & 0.275 & -0.016 & -0.269 \\
\hline & $(0.029)$ & $(0.439)$ & $(0.025)$ & $(0.380)$ & $(0.027)$ & $(0.299)$ \\
\hline \multirow[t]{2}{*}{ lnpgdp3 } & & -0.017 & & -0.012 & & 0.008 \\
\hline & & $(0.015)$ & & $(0.013)$ & & $(0.010)$ \\
\hline \multirow[t]{2}{*}{$\operatorname{lnfdi}$} & $0.124 * * *$ & $0.124 * * *$ & 0.049 & 0.049 & 0.077 & 0.077 \\
\hline & $(0.045)$ & $(0.045)$ & $(0.040)$ & $(0.040)$ & $(0.068)$ & $(0.068)$ \\
\hline \multirow[t]{2}{*}{$\operatorname{lnfdi} 2$} & $-0.012 * * *$ & $-0.013 * * *$ & $-0.005^{*}$ & $-0.005^{*}$ & -0.006 & -0.006 \\
\hline & $(0.003)$ & $(0.003)$ & $(0.003)$ & $(0.003)$ & $(0.004)$ & $(0.004)$ \\
\hline \multirow[t]{2}{*}{ Industry } & 0.001 & 0.000 & 0.003 & 0.003 & -0.014 & -0.014 \\
\hline & $(0.010)$ & $(0.010)$ & $(0.009)$ & $(0.009)$ & $(0.012)$ & $(0.012)$ \\
\hline \multirow[t]{2}{*}{ Services } & -0.001 & 0.000 & -0.000 & 0.001 & -0.011 & -0.012 \\
\hline & $(0.012)$ & $(0.012)$ & $(0.010)$ & $(0.010)$ & $(0.013)$ & $(0.013)$ \\
\hline \multirow[t]{2}{*}{ lneconomy } & $-1.653 * * *$ & $-1.691 * * *$ & -0.519 & -0.545 & -0.904 & -0.885 \\
\hline & $(0.270)$ & $(0.280)$ & $(0.366)$ & $(0.370)$ & $(0.807)$ & $(0.813)$ \\
\hline \multirow[t]{2}{*}{ lnpop } & $1.522 * * *$ & $1.485^{* * *}$ & 0.430 & 0.405 & $1.145^{*}$ & $1.163^{*}$ \\
\hline & $(0.262)$ & $(0.267)$ & $(0.296)$ & $(0.295)$ & $(0.692)$ & $(0.692)$ \\
\hline \multirow[t]{2}{*}{ Constant } & $-16.913 * * *$ & 0.051 & -3.028 & 8.429 & -4.720 & -13.056 \\
\hline & $(6.145)$ & $(15.596)$ & $(6.278)$ & $(13.809)$ & $(12.817)$ & (14.707) \\
\hline Time variables & Yes & Yes & Yes & Yes & Yes & Yes \\
\hline$F$-test for $T$ & 44.51 & 44.38 & 42.99 & 42.90 & 11.64 & 11.42 \\
\hline Observations & 3589 & 3589 & 3589 & 3589 & 3589 & 3589 \\
\hline GDP turning point & N.A & N.A & $148,889.4$ & N.A & N.A & N.A \\
\hline FDI turning point & 175.33 & 117.83 & 134.29 & 134.29 & N.A & N.A \\
\hline$R$-squared & 0.15 & 0.15 & 0.14 & 0.14 & 0.03 & 0.03 \\
\hline$F$-Statistics & 33.14 & 31.36 & 38.18 & 36.47 & 9.55 & 9.23 \\
\hline
\end{tabular}

Standard errors are in brackets and clustered at the city level

$*, * *$, and $* * *$ denote significance at the $10 \%, 5 \%$, and $1 \%$, respectively. 'NA' denotes coefficients are not significant, excluding turning points 
The coefficient of the GDP per capita cubic term in Model (3) is not significant. This study reveals that there is not a significant cubic function relationship, in neither the $\mathrm{N}$-shaped curve nor the inverse one, between pollutant emission or discharges and per capita GDP. Based on the significant level of regression, we can conclude that Model (2) is better fitting than Model (3).

Regression results of Model (2) show that the coefficient of the industrial $\mathrm{SO}_{2}$ emission quadratic term is negative, which means there is an inverted $U$ curve relationship between pollutant emission or discharge and per capita GDP, and it fits the classical Kuznets curve. This suggests that with the development of the economy, emission of this pollutant rises as per capita GDP grows in the initial stage, but will drop as the economy keeps developing to a certain degree. Moreover, there is also an inverted $U$ curve between industrial dust emissions and per FDI and it is the same in the case of industrial $\mathrm{SO}_{2}$ discharge. However, the quadratic coefficient is not significant. For the discharge of industrial dust and the effluent, only the parameters of the linear terms are positive and significant on GDP per capita, showing that the development of the economy will worsen environmental pollution.

In the inverted $\mathrm{U}$ curve of industrial $\mathrm{SO}_{2}$ emission, the turning point of the quadratic curve appears at about 148 ,
889.3RMB of per capita GDP. According to the Statistical Bulletin on 2017 National Economic and Social Development compiled by the National Bureau of Statistics of China, national GDP per capita is 53, $980 \mathrm{RMB}$ in 2016, which is obviously lower than that of the turning point. After comparing the average GDP per capita of 290 cities from 2003 to 2016, we find that at present the majority of cities in China lie left of the turning point of this environmental Kuznets curve, except for Shenzhen, Dongguan of Guangdong Province, and Karamay of Xinjiang Uygur Autonomous region. Two of the three cities are in the highly developed areas, and Karamay is located to the right as a result of its small population (Fig. 2). This phenomenon draws a general conclusion that the environment is being improved with the economic growth in the most developed provinces (Wang et al. 2017). There is still a large room to improve the environmental quality for those cities located on the left of the turning point.

In terms of the relationship between FDI and pollutant emission or discharge, analysis results show that there is an inverted U-shaped relation. In China's early stage of economic opening, the increase in foreign investment could damage the environment. However, as economic openness and FDI further increase, environmental quality would begin to be improved. Currently, the FDI turning point in China (a)

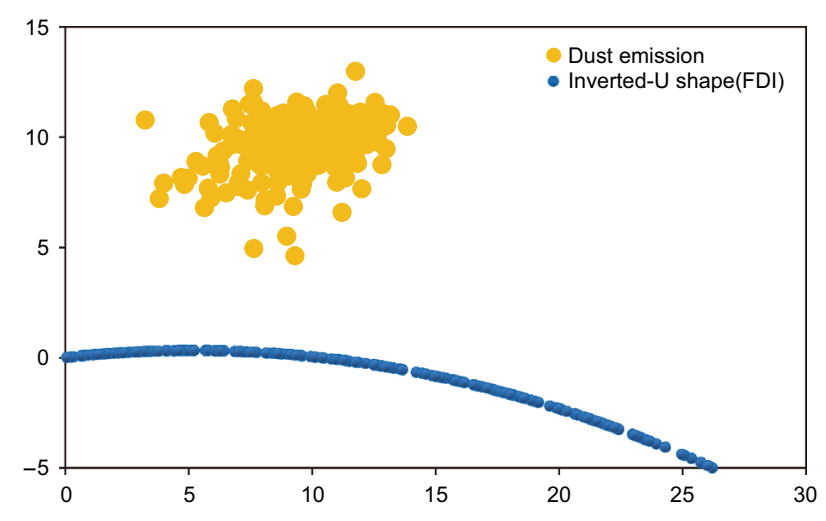

(b)

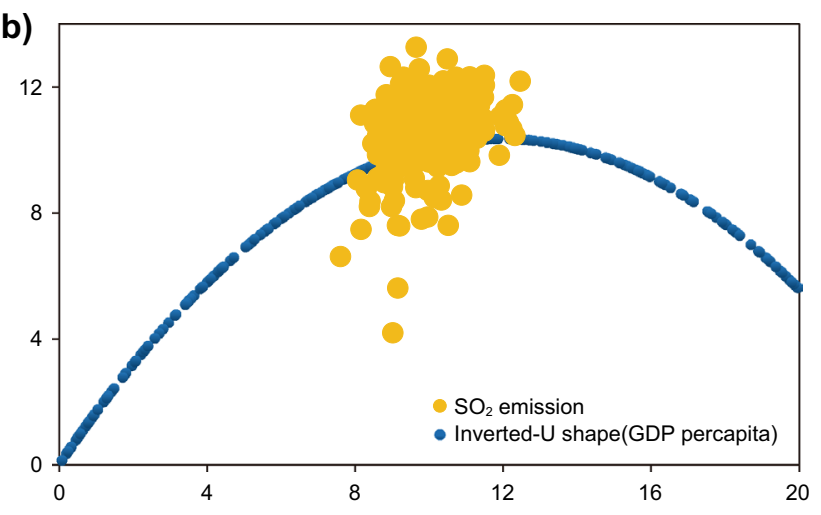

(c)

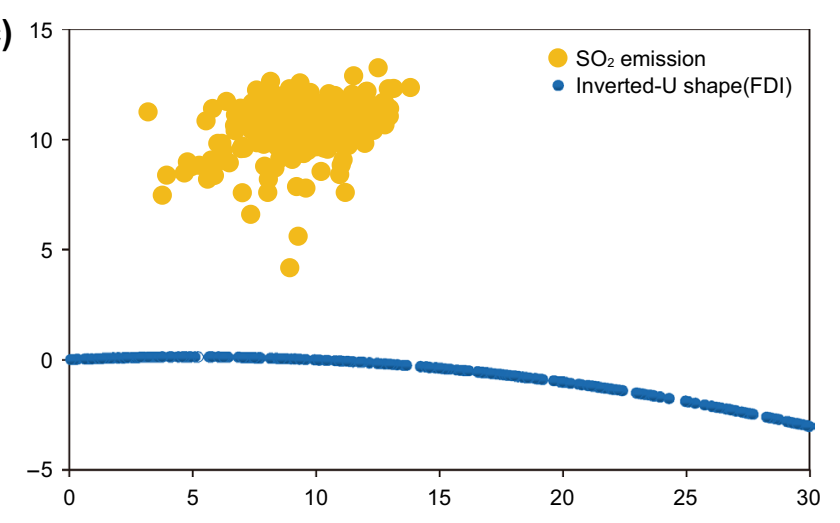

Fig. 2 Relationships between economic development and pollutants emission 
is 1753.3 thousand US dollars in the regression of industrial dust emission, and the point of industrial $\mathrm{SO}_{2}$ emission is at about 1342.9 thousand US dollars. In the case of industrial effluent discharge, the turning point appears not so significant.

According to the data analysis of FDI, the points of 276 cities are located on the right side of the industrial dust Kuznets curve, and the points of 278 cities are located on the right side of the inverted $\mathrm{U}$ curve. In the case of industrial $\mathrm{SO}_{2}$ emission, the parameters of emission of industrial effluent are not significant as well (Fig. 2).

Due to the faulty policies of attracting FDI in the early twenty-first century, most governments tended to overlook the environmental issues in China, which contributed to such a situation. Unfortunately, this problem resulted in pollution coming along with an increase in foreign investment. In recent years, with the change of people's opinions and the upgrading of the Chinese industrial structure, environmental protection has been increasingly emphasized in foreign investment. Because of the spillover effect of technology and management brought by the FDI, environmental pollution was reduced by using advanced technologies.

In terms of industrial structure, regression results of different models are similar. The positive coefficients on the secondary industry suggest that pollutant emission or discharge could rise with the growing proportion of the secondary industry. However, these coefficients are not so significant. Pollutant emission or discharge in China is increasing as a result of the underdevelopment of the service sector and the rapid growth of high energy-consuming industries. The effect of the growing population on industrial dust and effluent discharge is significantly positive, which indicates that pollutant emission or discharge also goes up with the increase in population. However, in terms of its effects on industrial $\mathrm{SO}_{2}$ emissions, the parameters are of the same signs but also specifically insignificant. The population boom will enlarge the city and bring about an increase in energy consumption, which is bound to influence the environment. As for the effect of economic density on the environment, the coefficients of the results were negative significantly, showing that higher economic density will reduce the emission of industrial dust. Cases are similar in the discharge of industrial $\mathrm{SO}_{2}$ and industrial effluent: regression coefficients of the economy density are negative but insignificant, as we can see in Table 5. Because not all these coefficients are significant, it is difficult to illustrate the influence of economic density on environmental pollution in a general scope.

\subsection{Empirical results of analyzing samples}

Due to the considerable differences in economic development levels in cities, the influences caused by economic development on the environment vary accordingly. To investigate the heterogeneity on the economic development level, we divide the sample into two subsamples to study the heterogeneous influences. In general, provinces in eastern China are more developed than those in the central and western areas. In terms of industrial structure, the eastern area is also better than the central and western areas, which has been proved in the statistics of variables above. Given the economic development difference and availability of data, this study analyzes the more developed cities and less developed cities. According to the mean value of GDP per capita throughout the sample period, we choose 22,155 RMB as the cutoff and divide the sample into high-level and lowlevel samples. This aims to identify the relationship between economic growth and environmental pollution separately.

Before conducting regressions, the Hausman test of cluster-robust standard errors is applied to demonstrate whether the fixed-effect model or the random-effect model should be used. According to the regression analysis, this study found that the regression effect of Model (2) is better than Model (3). Thus, we use Model (2) to run the regression of subsamples. The results of the Hausman tests are shown in Table 6 .

According to the results in Table 6, we have to reject the null hypothesis at the 5\% significance level for all the cities in different subsamples. Specifically, the Hausman test results of regression on industrial dust and industrial effluent are significant at the $1 \%$ level, and only the regression on industrial $\mathrm{SO}_{2}$ with the more developed samples is significant at the 5\% level. In other words, the fixed-effect model should be chosen in subsample regressions. This study runs separated subsample regressions for three kinds of pollutants, and results are shown in Table 7.

Table 6 Results of Hausman tests

\begin{tabular}{|c|c|c|c|c|c|c|}
\hline \multirow{2}{*}{$\begin{array}{l}\text { Explained variables } \\
\text { Regression models }\end{array}$} & \multicolumn{2}{|l|}{ Lndust } & \multicolumn{2}{|l|}{$\operatorname{lnso} 2$} & \multicolumn{2}{|l|}{ lneffluent } \\
\hline & High & Low & High & Low & High & Low \\
\hline Sargan-Hansen Stat & 37.72 & 64.35 & 34.79 & 138.77 & 41.08 & 59.64 \\
\hline$P$ value & 0.0096 & 0.0000 & 0.0213 & 0.0000 & 0.0036 & 0.0000 \\
\hline Conclusion & Fixed-effect model & & Fixed-effect model & & Fixed-effect model & \\
\hline
\end{tabular}


Table 7 Empirical analysis results for different samples

\begin{tabular}{|c|c|c|c|c|c|c|}
\hline \multirow[t]{3}{*}{ Variable } & (1) & $(2)$ & (3) & (4) & $(5)$ & (6) \\
\hline & \multicolumn{2}{|c|}{ Industrial dust emission } & \multicolumn{2}{|c|}{ Industrial SO2 emission } & \multicolumn{2}{|c|}{ Effluent emission } \\
\hline & High & Low & High & Low & High & Low \\
\hline \multirow[t]{2}{*}{ lnpgdp } & $6.139 * * *$ & 1.502 & $5.404 * * *$ & 1.628 & 1.534 & $3.084 * *$ \\
\hline & $(2.050)$ & $(1.695)$ & $(1.765)$ & $(1.507)$ & $(2.463)$ & $(1.373)$ \\
\hline \multirow[t]{2}{*}{ lnpgdp2 } & $-0.211 * *$ & -0.070 & $-0.230 * * *$ & -0.119 & -0.009 & -0.071 \\
\hline & $(0.089)$ & $(0.081)$ & $(0.076)$ & $(0.074)$ & $(0.100)$ & $(0.061)$ \\
\hline \multirow[t]{2}{*}{$\operatorname{lnfdi}$} & $0.307 * *$ & 0.066 & $0.183 * *$ & 0.030 & 0.024 & -0.010 \\
\hline & $(0.124)$ & $(0.046)$ & $(0.092)$ & $(0.038)$ & $(0.123)$ & $(0.047)$ \\
\hline \multirow[t]{2}{*}{$\operatorname{lnfdi} 2$} & $-0.022 * * *$ & -0.007 & $-0.012 * *$ & -0.004 & -0.003 & -0.001 \\
\hline & $(0.007)$ & $(0.005)$ & $(0.005)$ & $(0.004)$ & $(0.006)$ & $(0.005)$ \\
\hline \multirow[t]{2}{*}{ lndustry } & 0.018 & -0.001 & 0.004 & -0.005 & 0.021 & $-0.027 *$ \\
\hline & $(0.028)$ & $(0.015)$ & $(0.022)$ & $(0.011)$ & $(0.032)$ & $(0.014)$ \\
\hline \multirow[t]{2}{*}{ Service } & 0.006 & -0.009 & -0.012 & -0.002 & 0.020 & -0.019 \\
\hline & $(0.031)$ & $(0.017)$ & $(0.024)$ & $(0.012)$ & $(0.031)$ & $(0.014)$ \\
\hline \multirow[t]{2}{*}{ lneconomy } & $-1.491 * *$ & -0.448 & -0.609 & 0.496 & -1.631 & -1.188 \\
\hline & $(0.578)$ & $(0.477)$ & $(0.705)$ & $(0.598)$ & $(1.593)$ & $(0.946)$ \\
\hline \multirow[t]{2}{*}{ lnpop } & $1.278 * *$ & 0.344 & 0.326 & -0.328 & 1.163 & $2.029 * *$ \\
\hline & $(0.504)$ & $(0.652)$ & $(0.495)$ & $(0.665)$ & $(1.171)$ & $(1.028)$ \\
\hline \multirow[t]{2}{*}{ Constant } & $-41.926 * * *$ & -0.718 & -21.534 & 7.784 & -5.220 & -26.877 \\
\hline & $(15.277)$ & $(16.517)$ & $(13.678)$ & $(15.062)$ & $(25.080)$ & (19.543) \\
\hline Time variables & Yes & Yes & Yes & Yes & Yes & Yes \\
\hline$F$-test for $T$ & 28.04 & 9.71 & 31.32 & 6.63 & 8.17 & 2.38 \\
\hline Observations & 1756 & 1833 & 1756 & 1833 & 1756 & 1833 \\
\hline GDP turning point & $2,078,991$ & N.A & 126,478 & N.A & N.A & N.A \\
\hline FDI turning point & 1072 & N.A & 2048 & N.A & N.A & N.A \\
\hline$R$-squared & 0.24 & 0.09 & 0.24 & 0.05 & 0.06 & 0.02 \\
\hline$F$-statistic & 24.33 & 7.41 & 36.68 & 8.24 & 8.89 & 2.38 \\
\hline
\end{tabular}

Standard errors are in brackets and are clustered at the city level

The "high" group means that the average level of GDP per capita is higher than the cutoff, and the "low" group means that the average level of GDP per capita is lower than the cutoff of the full sample

$*, * *$, and $* * *$ denote significance at the $10 \%, 5 \%$, and $1 \%$ level, respectively. 'N.A.' denotes that the regression coefficients are not significant, excluding turning points

According to the results of subsample regressions, the relationship between industrial dust emission and GDP per capita as well as the relationships between industrial dust emission and FDI in more developed cities is shown as an inverted U-shaped curve. These parameters are significant at the 5\% level. For industrial $\mathrm{SO}_{2}$ emission, the relationship between these pollutant emissions or discharge and GDP per capita and FDI fits an inverted U curve in more developed cities. For the regressions based on industrial effluent discharge, we do not expect an inverted U-shaped curve for the relationship between the pollutant emission and GDP per capita or FDI; this means that the air pollution caused by the economic development is more severe than the effluent pollution. Meanwhile, despite an inverted U-shaped relationship between pollutant emission and GDP per capita or
FDI of the cities in the less developed level, the regression coefficients are not significant at all, which means that the economic development will not pollute the environment significantly.

These inverted curve relationships indicate that the environment is getting better while more foreign investment is being introduced to these cities along with economic development. Comparing more developed cities with less developed cities, we can find that the regression coefficients of GDP per capita in the more developed area are larger and more significant than those of less developed cities. It means that the influence of economic growth on environmental pollution in the more developed cities is more considerably significant than that of less developed cities. 
Since the Kuznets curves for different pollutant emissions are different, the turning point also varies. In the process of searching for the turning point, this study excludes the curves without significant regression coefficients. In the aspect of economic growth concerning industrial dust emission and GDP per capita, all spots of 290 cities are located on the left side of the turning point of the curve. In other words, the emission of industrial dust increases as the economy develops in the more developed cities. In terms of industrial $\mathrm{SO}_{2}$ emission in these more developed areas, only 23 spots among 290 cities are on the right side of the turning point, and in these cities, pollutant emission or discharge decreases as the economy grows.

As for the FDI, the coefficient showing the relationship between pollutant emission or discharge and FDI in the less developed area is not significant, and in more developed areas, only 68 spots of cities are located on the right side of this curve. In addition, 163 cities' spots lie left of the inverted U curve of industrial dust emission, and 166 cities' spots are on the left of the curve concerning industrial $\mathrm{SO}_{2}$ discharge as well. This suggests that those cities on the left side are in a period of economic structural adjustment, in which the relationship between FDI and environmental pollution has been strengthening. As for the industrial effluent discharge, there is no such significant relationship between these two. As for the regional distribution, we further analyze the distribution of all the locations of these cities to show the present situation of China's environmental pollution. We observe the ratios of cities' spots that lie on the left side of the EKC in Fig. 3. Noticing that only a few of these points are on the right side of the EKC relative to the GDP per capita, and so we plot the figures of ratios of the cities' spots on the left side of EKC relative to FDI.

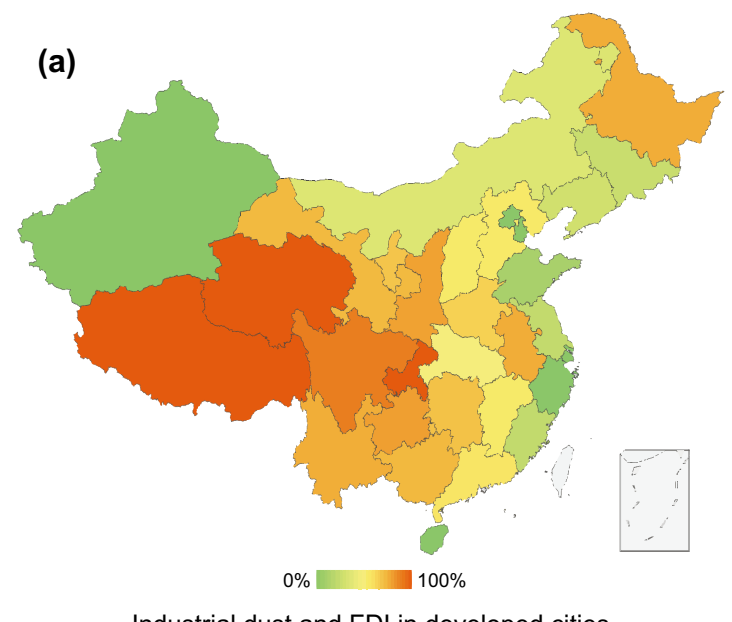

Industrial dust and FDI in developed cities
Figure 3 shows that the FDI has reached a high level in the developed cities, especially for the cities in the east coast areas, like Jiangsu, Zhejiang, and Fujian provinces, because most of the cities' spots in these provinces are on the right of the Kuznets curve's turning point. Moreover, there is a downward trend in industrial $\mathrm{SO}_{2}$ emission and industrial dust discharge with the introduction of more FDI, with the exception of Xinjiang Province. The majority of the cities lie on the right side of the curve. The reason is that there are only two cities recorded in the sample: Urumchi and Karamay. These two cities are imbued with resources and attract a lot of FDI, so their FDI level is higher than any of the other cities. According to the relationship between FDI and pollutant emission or discharge in inland areas, China is at the transforming stage, with some cities' spots on the right of the turning point of the FDI curve and others on the left. Those on the left side of the curve are facing the situation in which pollution is getting more severe with the increase in FDI. The contradiction between pollution and economic growth in eastern cities is far less concerning than that in inland cities.

When it comes to industrial structure, their regression coefficients are positive in the more developed cities but negative in the less developed cities; yet both of these coefficients are not significant at all, showing that the industrial structure may not be the main reasons affecting the environmental quality. Neither the secondary industry proportion nor the service industry proportion plays a vital role in pollution. Moreover, there is a significant difference in the influence of population on pollutant emission or discharge between more developed areas and less developed areas. The influence of the population on environmental pollution can be summarized as: emission or discharge of the two major pollutants usually rises with the increase in population. In

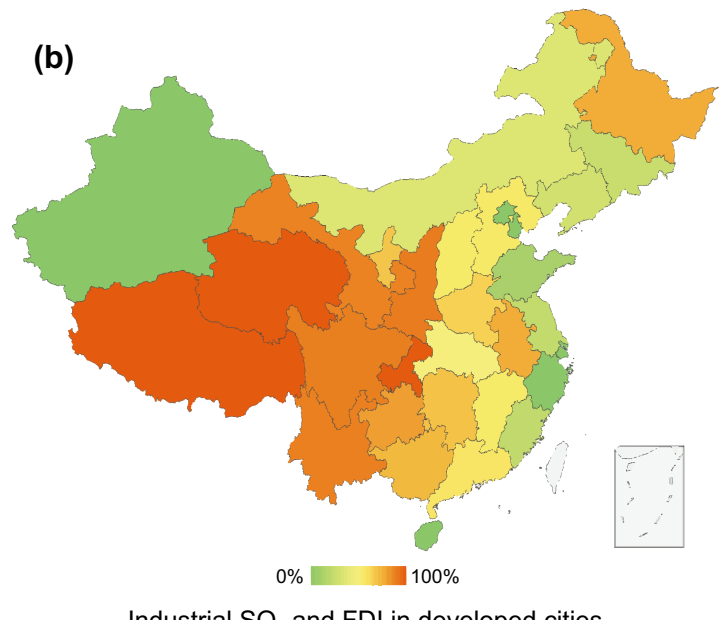

Industrial $\mathrm{SO}_{2}$ and FDI in developed cities

Fig. 3 Ratios of the cities' spots lie on the left side of the EKC of FDI. a Industrial dust and FDI in developed cities. b Industrial SO 2 and FDI in developed cities 
contrast, a $1 \%$ increase in population will result in a $1.278 \%$ increase in industrial dust emission in a more developed area. In terms of industrial effluent discharge, the influence of population growth is massive in those less developed areas. For the effect of economic density, the change of economic density shows no consistent effects on environmental pollution, which is similar to the conclusion of full sample analyses. The rise in economic density could either raise or reduce pollutants emission and discharge, and the significance of coefficients is considerably different. Hence, its influence on the environment is not consistent.

\section{Conclusions and policy suggestions}

By analyzing the panel data of 290 cities in China from 2003 to 2016, this study reveals the relationship between economic growth and pollution, including industrial dust emission, industrial $\mathrm{SO}_{2}$ emission, and industrial effluent discharge. Through the empirical analysis with the fixedeffect regression model, the conclusions can be drawn as below: (1) relationship between economic growth and environmental pollution is supported by an Inverted-U shaped Kuznets curve, and these relationships vary with different pollutants. (2) In terms of economic openness, the relationship between the pollutant emission or discharge and foreign direct investment is supported by an inverted $\mathrm{U}$-shaped curve. Pollution levels of most cities' spots are located on the left of the curve, where pollutant emission or discharge rises as GDP per capita and FDI increases. (3) The population boom generally results in the growth of pollutant emission or discharge. This increase in pollutant emission or discharge might be a high proportion of secondary. (4) According to the subsample analysis results, the development of the economy will lead to pollution in more developed cities rather than in less developed cities, and the influence of economic density on pollutant emission or discharge is significantly inconsistent.

In order to reconcile the need for sustainable growth of the economy with concern for the environment, we must be aware of the pollution level of China in the process of economic growth. We analyze the relationship between economic growth and pollution by different subsamples and three different pollutants. There are some implications we can draw from the results of this study.

First, because of the Inverted-U relationship between GDP per capita, FDI, and pollution, we need to follow the economic development rules. Comparing those more developed areas with the less developed areas, we can discern that the reaction of environmental pollution to economic growth is more sensitive in more developed regions and cities. Therefore, in the process of introducing foreign investment, it is necessary to be aware of environmental pollution.
Meanwhile, the governments in China should improve development modes and enhance regulations to reduce environmental pollution.

Second, in terms of the influence of industrial structure on the economy, considering the relatively high emission of $\mathrm{SO}_{2}$ and dust, it is necessary to accelerate the up-gradation of industrial structure. Policy-makers and governments should support the development of the service sector, such as the hospitality industry, information technology, and financial services. In manufacturing industries, the introduction of technology must be strengthened, and pollutant emission or discharge should be reduced by adopting environmentally friendly technologies. It has been founded that adopting green technology is a sustainable way to achieve a low-carbon or carbon-free environment (Sun et al.2019). It is an excellent way to adopt some environmentally friendly energies like geothermal energy and solar energy (Zhang et al. 2019; Li et al. 2019). Other literature also suggested using natural gas or electric vehicles in transportation to reduce pollutant emissions (Yuan et al. 2018; Zhang et al. 2018). Meanwhile, environmental non-governmental organizations may help to enhance urban environmental governance significantly ( $\mathrm{Li}$ et al. 2018).

Third, as a result of the absence of regulation, environmental pollution becomes worse when the economy takes off. Based on our findings, we have to take economic growth, opening-up policy, and population into consideration when imposing regulations and making environmental policies.

Acknowledgements The authors are grateful to the editor and anonymous reviewers for their insightful comments. This work was financially supported by the Major Program of National Social Science Foundation (No. 16ZDA006), National Natural Science Foundation of China (Nos. 71603193 and 71974151), and Teaching and Research Project of Wuhan University (No. 1201-413200127).

\section{Compliance with ethical standards}

Conflict of interest The authors declare that they have no conflict of interest.

Open Access This article is licensed under a Creative Commons Attribution 4.0 International License, which permits use, sharing, adaptation, distribution and reproduction in any medium or format, as long as you give appropriate credit to the original author(s) and the source, provide a link to the Creative Commons licence, and indicate if changes were made. The images or other third party material in this article are included in the article's Creative Commons licence, unless indicated otherwise in a credit line to the material. If material is not included in the article's Creative Commons licence and your intended use is not permitted by statutory regulation or exceeds the permitted use, you will need to obtain permission directly from the copyright holder. To view a copy of this licence, visit http://creativecommons.org/licenses/by/4.0/. 


\section{References}

Antweiler W, Copeland BR, Taylor MS. Is free trade good for the environment? Am Econ Rev. 2001;91(4):877-908. https://doi. org/10.1257/aer.91.4.877.

Apergis N, Ozturk I. Testing environmental Kuznets curve hypothesis in Asian countries. Ecol Indic. 2015;52:16-22. https://doi. org/10.1016/j.ecolind.2014.11.026.

Apergis N. Environmental Kuznets curves: New evidence on both panel and country-level CO2 emissions. Energy Econ. 2016;54:263-71. https://doi.org/10.1016/j.eneco.2015.12.007.

Aslanidis N, Iranzo S. Environment and development: is there a Kuznets curve for $\mathrm{CO}_{2}$ emissions? Appl Econ. 2009;41(6):80310. https://doi.org/10.1080/00036840601018994.

Brock WA, Taylor MS. The green Solow model. J Econ Growth. 2010;15(2):127-53. https://doi.org/10.1007/s10887-010-9051-0.

Cai F, Du Y, Wang MY. The political economy of emission in China: will a low carbon growth be incentive compatible in next decade and beyond. Econ Res J. 2008;6:4-11. https://doi.org/10.1007/ BF00546775.

Chen SY. Energy-save and emission-abate activity with its impact on industrial win-win development in China: 2009-2049. Econ Res J. 2010;45(3):129-43 (in Chinese).

Churchill SA, Inekwe J, Ivanovski K, et al. The environmental Kuznets curve in the OECD: 1870-2014. Energy Econ. 2018;75:389-99. https://doi.org/10.1016/j.eneco.2018.09.004.

Coondoo D, Dinda S. Causality between income and emission: a country group-specific econometric analysis. Ecol Econ. 2002;40(3):351-67. https://doi.org/10.1016/s0921 -8009(01)00280-4.

Copeland BR, Taylor MS. North-South trade and the environment. Q J Econ. 1994;109(3):755-87. https://doi.org/10.2307/2118421.

Dietz T, Rosa EA. Environmental impacts of population and consumption. Environ Signif Consump Res Dir. 1997. https://doi. org/10.17226/5430.

Dinda S. Environmental Kuznets curve hypothesis: a survey. Ecol Econ. 2004;49(4):431-55. https://doi.org/10.1016/j.ecole con.2004.02.011.

Ding JH, Nian Y. The investigation of economic growth and environmental pollution-illustrated by the case of Jiangsu Province. Nankai Econ Stud. 2010;2:64-79. https://doi.org/10.3969/j. issn.1001-4691.2010.02.005(in Chinese).

Dong KY, Sun RJ, Li H, et al. A review of China's energy consumption structure and outlook based on a long-range energy alternatives modeling tool. Pet Sci. 2017;14(1):214-27. https://doi. org/10.1007/s12182-016-0136-z.

Dou J, Han X. How does the industry mobility affect pollution industry transfer in China: empirical test on pollution haven hypothesis and porter hypothesis. J Clean Prod. 2019;217:105-15. https://doi.org/10.1016/j.jclepro.2019.01.147.

Galeotti M, Manera M, Lanza A. On the robustness of robustness checks of the environmental Kuznets curve hypothesis. Environ Resour Econ. 2009;42(4):551. https://doi.org/10.1007/s1064 0-008-9224-x.

Grossman GM, Krueger AB. Economic growth and the environment. Q J Econ. 1995;110(2):353-77. https://doi.org/10.2307/21184 43.

He J. What is the role of openness for China's aggregate industrial $\mathrm{SO}_{2}$ emission? A structural analysis based on the Divisia decomposition method. Ecol Econ. 2010;69(4):868-86. https://doi. org/10.1016/j.ecolecon.2009.10.012.

$\mathrm{Hu} \mathrm{H}$, Jin Q, Kavan P. A study of heavy metal pollution in China: current status, pollution-control policies and countermeasures. Sustainability. 2014;6:5820-38. https://doi.org/10.3390/su6095820.
Hu H, Li X, Nguyen AD, et al. A critical evaluation of waste incineration plants in Wuhan (China) based on site selection, environmental influence, public health and public participation. Int J Environ Res Public Health. 2015;12(7):7593-614. https://doi.org/10.3390/ ijerph120707593.

$\mathrm{Hu} \mathrm{H}$, Xie N, Fang D, et al. The role of renewable energy consumption and commercial services trade in carbon dioxide reduction: evidence from 25 developing countries. Appl Energy. 2018;211:1229-444. https://doi.org/10.1016/j.apene rgy.2017.12.019.

Javorcik BS, Wei SJ. Pollution havens and foreign direct investment: dirty secret or popular myth? Contrib Econ Anal Policy. 2004. https://doi.org/10.2202/1538-0645.1244.

Jiang Y, Lei YL, Yang YZ, et al. Factors affecting the pilot trading market of carbon emissions in China. Pet Sci. 2018;15(2):412-20. https://doi.org/10.1007/s12182-018-0224-3.

Kang YQ, Zhao T, Yang YY. Environmental Kuznets curve for $\mathrm{CO}_{2}$ emissions in China: a spatial panel data approach. Ecol Indic. 2016;63:231-9. https://doi.org/10.1016/j.ecolind.2015.12.011.

Keller W, Levinson A. Pollution abatement costs and foreign direct investment inflows to US states. Rev Econ Stat. 2002;84(4):691703. https://doi.org/10.1162/003465302760556503.

Kuznets S. Economic growth and income inequality. Am Econ Rev. 1955;45(1):1-28. https://doi.org/10.1086/257662.

Li XS, Song ML, An QX. Heterogeneity study of the effect of China's economic growth on environmental pollution. Nankai Econ Stud. 2013;5:96-114. https://doi.org/10.14116/j.nkes.2013.05.001(in Chinese).

Li T, Wang Y, Zhao D. Environmental Kuznets curve in China: new evidence from dynamic panel analysis. Energy Policy. 2016;91:138-47. https://doi.org/10.1016/j.enpol.2016.01.002.

Li G, He Q, Shao S, et al. Environmental non-governmental organizations and urban environmental governance: evidence from China. J Environ Manag. 2018;206:1296-307. https://doi.org/10.1016/j. jenvman.2017.09.076.

Li Y, Zhang Q, Wang G, et al. Modeling and policy study for information asymmetry problem of photovoltaic module quality in China. Emerg Markets Finance Trade. 2019. https://doi. org/10.1080/1540496x.2019.1604337.

Liu HJ, Yan QY. Trade openness, FDI and China's carbon dioxide emissions. J Quant Tech Econ. 2011;28(3):21-35. https://doi. org/10.13653/j.cnki.jqte.2011.03.007(in Chinese).

Llorca M, Meunié A. $\mathrm{SO}_{2}$ emissions and the environmental Kuznets curve: the case of Chinese provinces. J Chin Econ Bus Stud. 2009;7(1):1-16. https://doi.org/10.1080/14765280802604656.

Ministry of Ecology and Environment of the People's Republic of China. Statistical Annual Report on Environment in 2018, 2019. Ministry of Ecology and Environment of the People's Republic of China. https://www.mee.gov.cn/hjzl/sthjzk/zghjzkgb/201905/ P020190619587632630618.pdf.

National Bureau of Statistics of the People's Republic of China. The China Statistical Yearbook, 2004-2017. https://www.stats.gov.cn/ tjsj/ndsj/ (2016).

Pal D, Mitra SK. The environmental Kuznets curve for carbon dioxide in India and China: growth and pollution at crossroad. J Policy Model. 2017;39(2):371-85. https://doi.org/10.1016/j.jpolm od.2017.03.005.

Panayotou T. Empirical tests and policy analysis of environmental degradation at different stages of economic development. International Labor Organization; 1993.

Selden TM, Song D. Environmental quality and development: is there a Kuznets curve for air pollution emissions? J Environ Econ Manag. 1994;27(2):147-62. https://doi.org/10.1006/jeem.1994.1031.

Shafik N, Bandyopadhyay S. Economic growth and environmental quality: time-series and cross-country evidence. World Bank Publications; 1992. 
Song T, Zheng TG, Tong LJ, et al. Environmental analysis of China's Provinces based on the panel data model. China Soft Sci. 2006;10:121-7. https://doi.org/10.3969/j. issn.1002-9753.2006.10.015.

Su ZF, Miao Y, Li Y. What cause china to become a pollution haven: evidence from Chinese provincial panel data. Econ Rev. 2011;3:97-104. https://doi.org/10.19361/j.er.2011.03.012(in Chinese).

Sun H, Edziah BK, Sun C, et al. Institutional quality, green innovation and energy efficiency. Energy Policy. 2019;135:111002. https:// doi.org/10.1016/j.enpol.2019.111002.

Wang Y, Han R, Kubota J. Is there an environmental Kuznets curve for $\mathrm{SO} 2$ emissions? A semi-parametric panel data analysis for China. Renew Sustain Energy Rev. 2016;54:1182-8. https://doi. org/10.1016/j.rser.2015.10.143.

Wang Y, Zhang C, Lu A, et al. A disaggregated analysis of the environmental Kuznets curve for industrial $\mathrm{CO}_{2}$ emissions in China. Appl Energy. 2017;190:172-80. https://doi.org/10.1016/j.apene rgy.2016.12.109.

World Bank. GDP (constant 2010 US\$), The World Bank Group. https ://data.worldbank.org/indicator/NY.GDP.PCAP.KD.

$\mathrm{Xu} \mathrm{T}$. Investigating environmental Kuznets curve in China-aggregation bias and policy implications. Energy Policy. 2018;114:31522. https://doi.org/10.1016/j.enpol.2017.12.027.

Yin J, Zheng M, Chen J. The effects of environmental regulation and technical progress on $\mathrm{CO}_{2}$ Kuznets curve: an evidence from
China. Energy Policy. 2015;77:97-108. https://doi.org/10.1016/j. enpol.2014.11.008.

Yuan JH, Zhou S, Peng TD, et al. Petroleum substitution, greenhouse gas emissions reduction and environmental benefits from the development of natural gas vehicles in China. Pet Sci. 2018;15(3):644-56. https://doi.org/10.1007/s12182-018-0237-y.

Zhang Y, Jiang DC. FDI, government regulation and water pollution in China-empirical tests based on the decomposed index of industrial structure and technology progress. Q J Econ. 2014;1:491514. https://doi.org/10.13821/j.cnki.ceq.2014.02.010(in Chinese).

Zhang Q, Li H, Zhu L, et al. Factors influencing the economics of public charging infrastructures for $\mathrm{EV}-\mathrm{a}$ review. Renew Sustain Energy Rev. 2018;94:500-9. https://doi.org/10.1016/j. rser.2018.06.022.

Zhang Q, Chen S, Tan Z, et al. Investment strategy of hydrothermal geothermal heating in China under policy, technology and geology uncertainties. J Clean Prod. 2019;207:17-29. https://doi. org/10.1016/j.jclepro.2018.09.240.

Zhu L, Hao Y, Lu ZN, et al. Do economic activities cause air pollution? Evidence from China's major cities. Sustain Cities Soc. 2019;49:101593. https://doi.org/10.1016/j.scs.2019.101593.

Zoundi Z. $\mathrm{CO}_{2}$ emissions, renewable energy and the Environmental Kuznets Curve, a panel cointegration approach. Renew Sustain Energy Rev. 2017;72:1067-75. 